$\mathbb{T}$ periodica polytechnica

Mechanical Engineering

$53 / 2(2009) 8185$

doi: 10.3311/pp.me.2009-2.05

web: http://www.pp.bme.hu/me

(c) Periodica Polytechnica 2009

RESEARCH ARTICLE

\section{Micromachining of micro and ultrafine-structured metals}

József Nyirő

Received 2010-01-18

\begin{abstract}
The microstructure of machined metals change near the tool affected zone. This paper presents some new results concerning mirror-like surface cutting of aluminum and copper. The microstructure of aluminum and copper represents the polycrystalline mild metals with face centered cubic (fcc) crystal lattice. The examination of mirror-like surface by optical microscopy, scanning electron microscopy, electron backscattered diffraction (EBSD) and atomic force microscopy show the grain boundaries and twin boundaries, which separates two domains for different crystal orientation. Young's modulus that depends on orientation can change considerably on these boundaries, consequently the value of elastic deformation of the layer under machined surface. This effect modified the roughness too. Aluminum and copper were cut as "conventional" micro-structured metals used in everyday practice and after so called ECAP process with ultrafine-crystalline structure, for examining effects of crystal size on machinability and surface integrity of machined mirror surfaces. Results of these comparative experiments are discussed in this paper.
\end{abstract}

\section{Keywords}

ultraprecision machining of mirror-like surfaces . copper . aluminum · crystal · micro and ultrafinestructure · dislocations . anisotropy $\cdot$ crystal orientation $\cdot$ surface integrity

\section{József Nyirő}

Department of Manufacturing Science and Technology, BME, H-1111 Budapest, Egry J. Str. 1., Hungary

e-mail: nyj@manuf.bme.hu

\section{Introduction}

Developments in the engineering industry and the high quality of its products make necessary the continuous improvement of the manufacturing processes involved and their economic efficiency.

Owing to the increased accuracy and quality of machined parts, investigations of the effect of cutting on the base material structure and its mechanical properties become absolutely necessary. It is well-known that material is plastically deformed under a cut surface and therefore its properties are changed. The effect of the material and its microstructure on the surface finish is especially strong when cutting ultraprecision mirror like surfaces. Mirror surface structural changes, such as grain boundaries on embedded phases, different orientations and anisotropy, may be observed leading to uneven surfaces. Deviations in materials structure always occur on the cut surface and therefore it is absolutely essential to investigate their effect, when machining very fine surfaces [5].

During ultraprecision cutting, due to very small chip sections, very often single crystals are cut. There is much research on single crystals that demonstrates that the chip undergoes much bigger and inhomogeneous plastic deformation than the cut surface layer, while plastic deformation takes place in some determined layers of the material (Fig. 1).

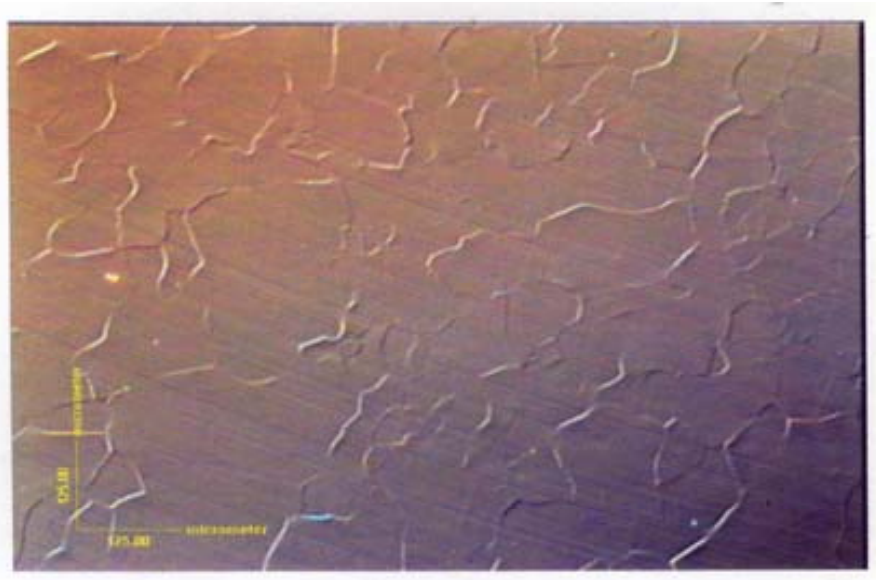

Fig. 1. Microcut surface by microscope (500X) 
Machining of micro structured copper and aluminum for analyzing effects of anisotropy, crystal lattice and mechanical behavior of different materials cutting experiments were made. The $\mathrm{Al}$ and $\mathrm{Cu}$ specimens were fixed on a disk at diameter 160 $\mathrm{mm}$ in the chuck of the lathe, so the traces of the tool paths could be considered as parallel straight lines.

When machining mirror like surfaces the bigger the anisotropy of the modulus of elasticity of the material, the greater the surface roughness. However, the surfaces integrity is affected not only by the anisotropy of crystalline structure but also by all the parameters of plastic deformation involved. Therefore, the determination of structural changes occurring during ultra precision machining, together with the increased temperature in the machined surface layer may be useful for estimating the surface integrity of machined component.

The work utilized in cutting is a function of the plastic deformation of the material. Elastic deformation vanishes when the cutting tool moves away and the temperature increases. About $10 \%$ of the work spent for plastic deformation results in an increase in dislocations density, while the rest is used in increasing the temperature.

\section{Surface roughness in microturning at copper}

Two important material properties of copper are its cubic face-centered atomic lattice structure, and intense anisotropy. The Young modulus of copper is changing from $\mathrm{E}=66.71 \cdot 10^{3}$ $\mathrm{N} / \mathrm{mm}^{2}$ to $\mathrm{E}=192.33 \cdot 10^{3} \mathrm{~N} / \mathrm{mm}^{2}$ depending on the orientation of crystal planes. The smallest value can be measured in the $<100>$ direction, while the largest value is in the $<111>$ crystallographic direction. The variation of other mechanical material properties, such as relative strain $(\epsilon)$, tensile strength $(R m)$ and the modulus of shear elasticity $(G)$, similar to the Young modulus [3]. These facts are corresponding to single crystals. In case of polycrystalline materials the values above are only relevant inside crystal boundaries, accordingly inside individual crystal. During conventional cutting, the shear, plastic deformed zone is much greater than the average crystal dimensions; hence gliding is taking place over crystal boundaries.

In spite of this in micromachining and/or ultraprecision cutting the chip root dimensions are significantly smaller than the average grain size, which means that gliding is taking place inside the crystal boundaries. Since the crystallographic orientations of the grains are different, this anisotropy causes a change in the generated force during the cutting of different grains. After the cutting tool goes past, the grains spring back to different extents due to the elastic deformation. The effect is described on Fig. 2]after Moriwaki [1].

On the basis of the model many sections of the machined surface topography can be explained, however it does not give an explanation to the event that the large roughness peaks often originate in crystal boundaries. Spenrath's [2] explanation for this effect is that due to the stress field before and under the cutting tool dislocations start inside the grain boundaries, which
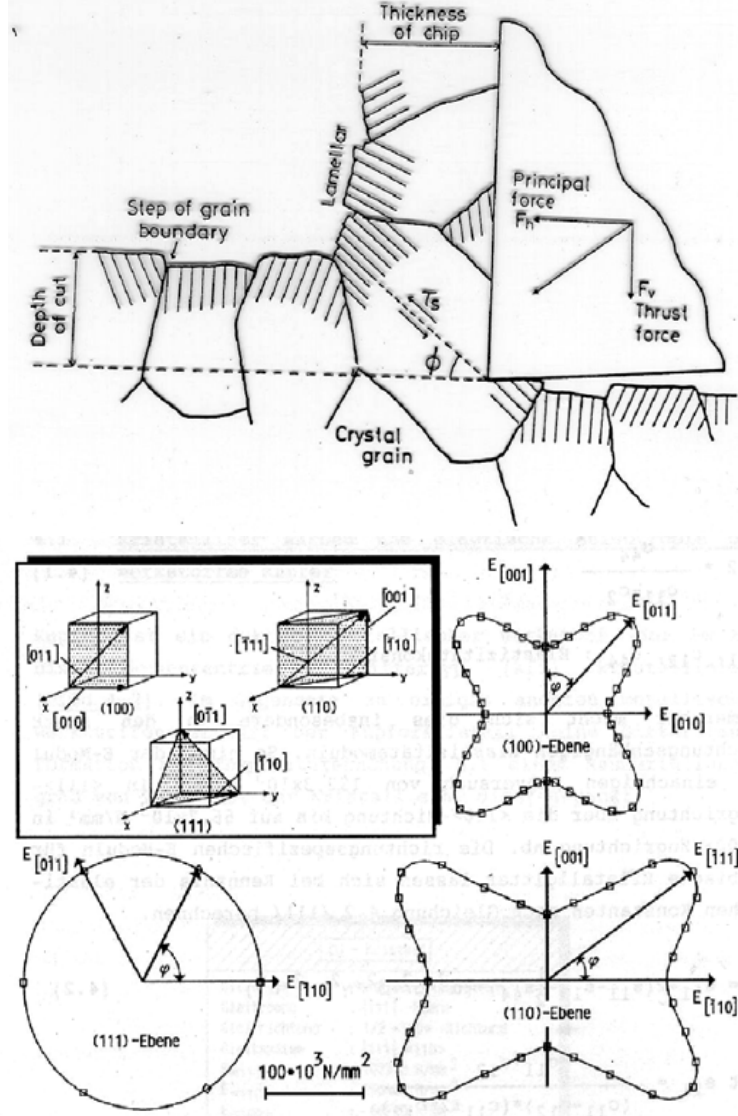

Fig. 2. The anisotropy of the materials and the spring-back effect (after Moriwaki [1])

are blocked at the crystal boundaries. The dislocations are piled up at crystal boundaries and increase locally the strength of the material. When the crystal boundary is cut, a larger force is produced, which induces greater elastic deformation, and this increased elastic deformation causes larger local spring back. Most of the effects can be explained with the theory of dislocation migration [4], but it still leaves some questions open. For example roughness peaks cannot be found at all the grain boundaries [6-8].

\section{Surface of copper specimens}

On the Fig. 3 etched macroscopic image of original state of the soft copper specimen is shown. In internal parts of its crystallites twins with parallel boundaries could be observed. Twins seen in the domain marked $\mathrm{E}$ is shown on Fig. 4 made by EBSD techniques. In the unit triangle of the stereographic pole figure, which is seen on Fig. 5identically marked poles of different domains (grains or twins) show their surface normals. On the Fig. 6one can see surfaces of Fig. 4 marked identically, showing clearly that tool, crossing crystal domains with different orientations changes the surface roughness to a less extent. As a result metallographic features become observable without any usual preparation only under effect of Nomarski differential interference contrast mode (N-DIC) of optical microscopy [13, 15].

Fig. 7.a made on mirror-like surface of copper specimen demonstrates, that the trace of the tool changes in every case, 


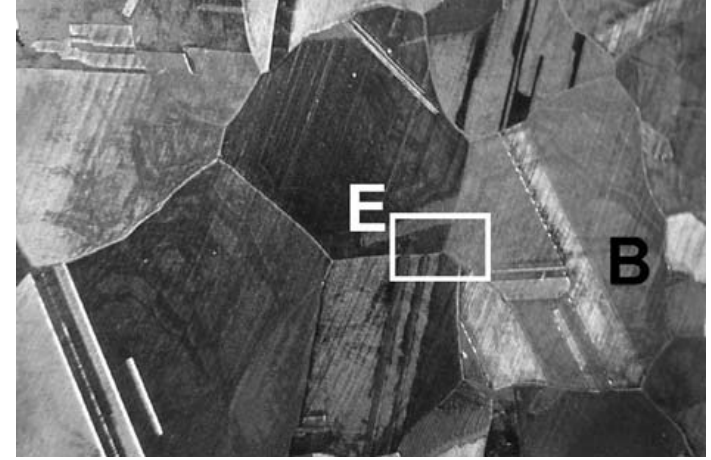

Fig. 3. Macroscopic image of original state of the annealed copper specimen.

when it crosses grain or twin boundary with changing crystallographic properties of domains to be machined. On the Fig. 7.a tool, moving from right to left, crosses at first a crystallite, then in the new crystallite it cuts the surface of a twin, making observable its both boundaries. Fig. 7.b made by atomic force microscopy (AFM) shows the 3D plot of a grain boundary on mirror cut surface of copper [16].

We get similar results with Al. Size, orientation and moduli E and $G$ have determinative effect on surface integrity during the machining.

\section{Experiments with ultrafine-structured metals}

The cutting experiments were made with submicroncrystallines $\mathrm{Al}$ and $\mathrm{Cu}$ ultrafine-crystallines structure was achieved as result of high rate of plastic deformation. In this paper author deals only with experiments on Al. For achieving ultrafine-structure the equal-channel angular pressing method was applied.

Equal-channel angular pressing (ECAP) is a processing method in which a metal is subjected to intense plastic straining through simple shear without any corresponding change in the cross-sectional dimensions of the sample. This procedure may be used to create ultra fine grain sizes in bulk polycrystalline materials.

The principles of the ECAP process have been examined with reference to the distortions introduced into a sample as it passes through an ECAP die with special attention to the effect of rotating the sample between consecutive passes. Significant distortions of the grain structure occurred when a sample passed through a standard ECAP die, so when a sample is pressed repetitively through the die, it has been recognized that the overall shearing characteristics within the crystalline sample may be changed by a rotation of the sample between the individual passes. The repetitive pressing of the same sample is generally carried out in order to attain very high imposed strains. At the same time there is an opportunity to rotate the sample between consecutive pressings in order to activate different shear planes and directions, thus enhancing the mechanical properties at room temperature by applying different routes [9, 10].

It is well-known that plastic deformation induced by conven-

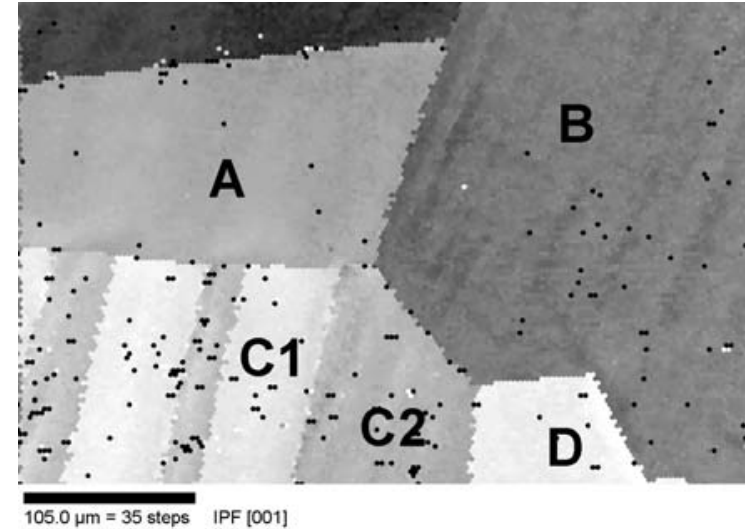

Fig. 4. EBSD image quality map of the detail E on the Fig. 3

tional forming methods can significantly increase the strength of metals. However, this increase is usually accompanied by a loss of ductility. It has been found recently that materials processed by ECAP after certain number of passes show high ductility along with high strength. Such unusual behavior of materials, which is in contradiction with 'classic' tendencies to lost ductility with increased strength, needs to be understood deeper. In this paper the effect of different routes of ECAP techniques on the strength and the ductility of an Albased alloy is investigated. The mechanical behaviour is related to the characteristic features of the ultrafine-crystalline microstructure formed during ECAP deformation [11].

The material used in this study was a commercial Al-Mg$\mathrm{Si}$ alloy (Al 6082). The main components of the alloy are $\mathrm{Al}$ (97\%), $\mathrm{Si}(0.7-1.3 \%), \mathrm{Mg}(0.6-1.2 \%)$ and $\mathrm{Mn}(0.4-1 \%)$. Before the ECAP deformation, the material was annealed at $420^{\circ} \mathrm{C}$ for 40 minutes. Specimens in this condition were regarded as the as-received material. Cylindrical billets of $15 \mathrm{~mm}$ in diameter and $145 \mathrm{~mm}$ in length were pressed through the ECAP die with $90^{\circ} \mathrm{C}$ intersecting channels. Four and eight passes were completed by the following routes: $\mathrm{BC}$ (rotation of the billet around its longitudinal axis after each pass by $90^{\circ} \mathrm{C}$ clockwise), BA (rotation of the billet around its longitudinal axis after each pass by $90^{\circ} \mathrm{C}$ clockwise and counterclockwise, alternatively) and C (rotation of the billet around its longitudinal axis after each pass by $180^{\circ} \mathrm{C}$, clockwise). The temperature of deformation was $293 \mathrm{~K}$ and the displacement rate of the billet was $8 \mathrm{~mm} / \mathrm{min}$ [12, 14].

It was found that ultrafine-sized microstructure (mean crystallite size $\sim 80 \mathrm{~nm})$ with high dislocation density $\left(3 \times 10^{14} \mathrm{~m}^{-2}\right)$ was achieved even after the first pass. The microstructure was refined only slightly during further ECAP passes. At the same time the dislocation density increased with the increase of ECAP deformation up to 4 passes. The dimensionless dislocation arrangement parameter, $\mathrm{M}$, has a value of $4.0 \pm 0.4$ for the asreceived specimen and it decreased to $2.2 \pm 0.3$ after 8 ECAP passes. This indicates that the dipole character of the dislocation structure became stronger with increasing deformation. 


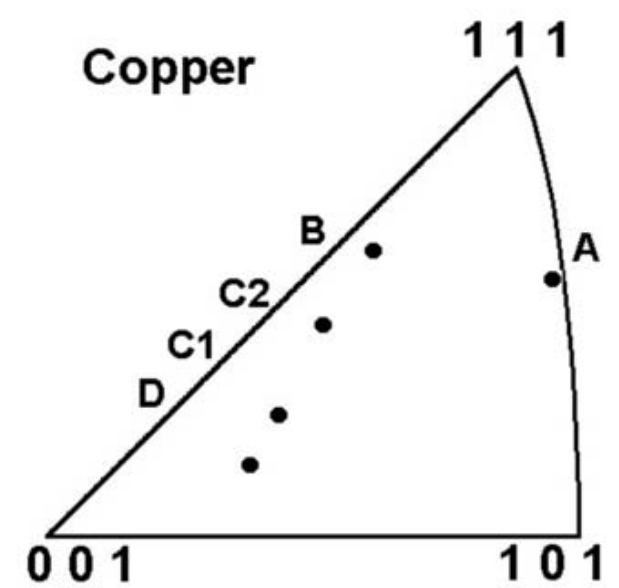

Fig. 5. Pole figure showing orientation of crystallites and twins marked on Fig. 3

\section{Surface integrity measurement}

The effect of crystal size and the ECAP process on the surface integrity was investigated by making mirror-like cylindrical and flat surfaces, using turning. An ultra-precision lathe (Csepel UP1) and Winter mono-crystalline diamond tool were used in these experiments.

The turning process has been applied to every specimen with the same cutting conditions.

The set machining parameters were:

$$
\begin{array}{ll}
\text { cutting speed }\left(\mathrm{v}_{c}\right) & 78 \mathrm{~m} / \mathrm{min} \\
\text { feedrate (f) } & 5 \mu \mathrm{m} / \mathrm{rev} \\
\text { cutting edge radius }\left(\mathrm{r}_{\beta}\right) & 50 \mathrm{~nm} .
\end{array}
$$

The sample surfaces, prepared by ultra-precision machining, demonstrated interesting changes. The original surface quality was nearly identical to that after the fourth pass. After eight passes, however, the surface roughness dropped by a factor of five, further reflecting the effect of the structural changes. In turning experiments after eight steps of pressing - under equal cutting conditions - cut surface roughness reduced by a factor of five on average (from $\mathrm{Ra}=55$ to $\mathrm{Ra}=10$ ).

The results can see on the next table (Table 1 ).

Tab. 1. Forming of surface roughness in function of ECAP number

\begin{tabular}{lll}
\hline No. of ECAP & $\begin{array}{l}\text { Average surface } \\
\text { roughness }(\mathrm{Ra}, \mathrm{nm})\end{array}$ & $\begin{array}{l}\text { Surface roughness } \\
(\mathrm{Rz}, \mathrm{nm})\end{array}$ \\
\hline 0 & 49,6 & 283,1 \\
1 & 54,8 & 402,9 \\
4 & 53,3 & 272,7 \\
8 & 9,5 & 70,87 \\
\hline
\end{tabular}

Surface roughness was measured with Atomic Force Microscope (Fig. 8). The results are very interesting and very promising: surface finish of the cut raw part had the same value.

\section{Conclusions}

For getting mirror like surfaces with ultrafinemeter size parameters of surface integrity one have to eliminate the influence

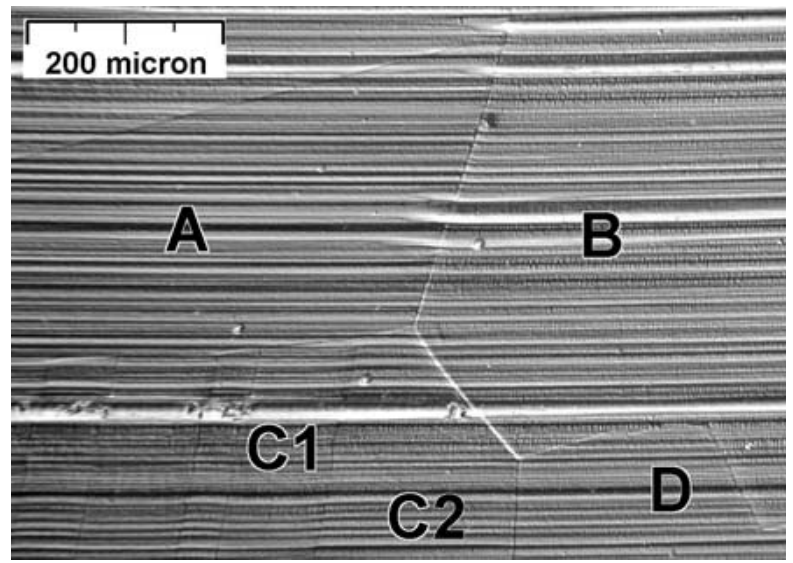

Fig. 6. N-DIC image of detail showing on Fig. 3 after ultra precision machining.

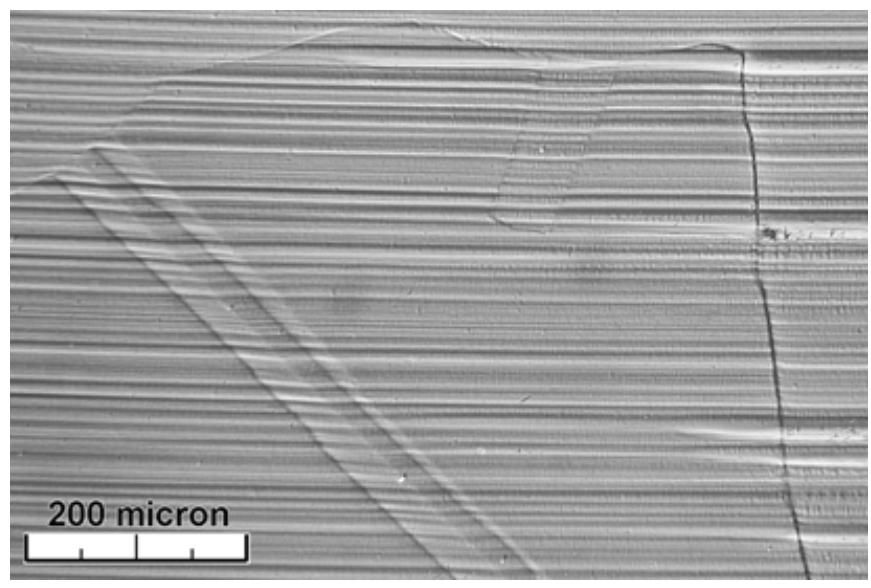

Fig. 7.a. N-DIC image of twin boundaries and grain boundaries on mirror cut surface.

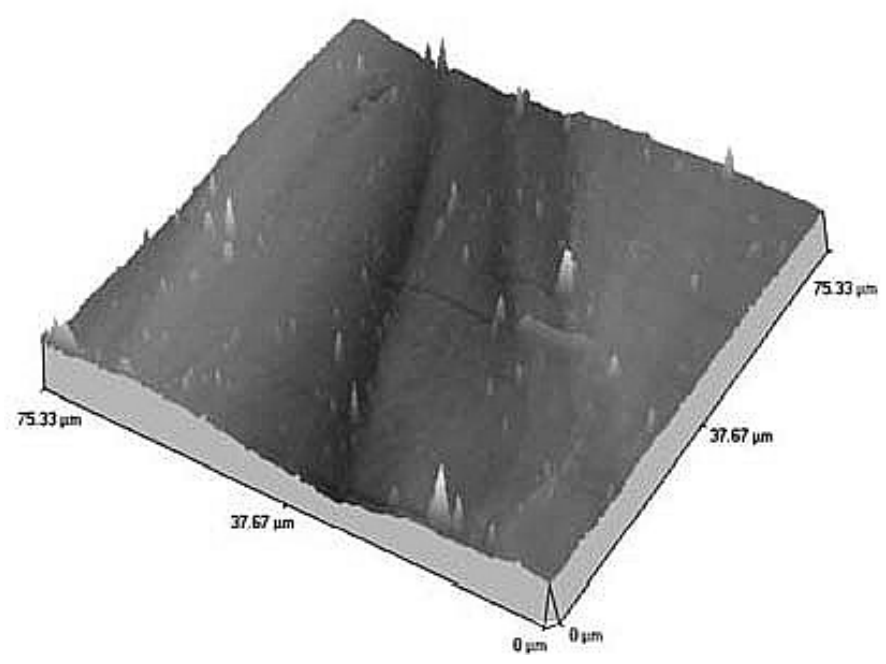

Fig. 7.b. 3D plot of a grain boundary on mirror cut surface.

of crystal orientation, different moduli of elasticity, anisotropy. The only possibility is to decrease the sizes of crystallines up to $100 \mathrm{~nm}$. They should be less, than active edge of cutting tool. In this case the tool edge is crossing many crystallines in one pass (feedrate is several $\mu \mathrm{m}$ ), and influences of different crystals neutralize those of each other. 


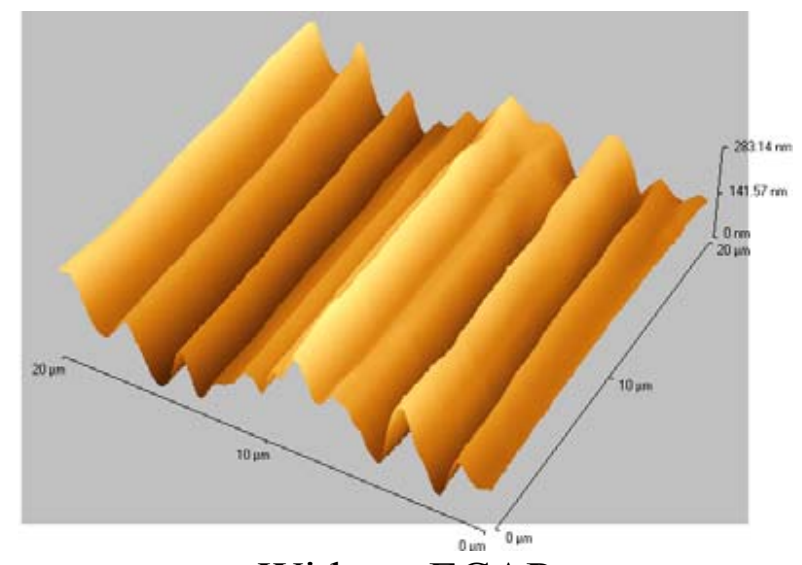

Without ECAP

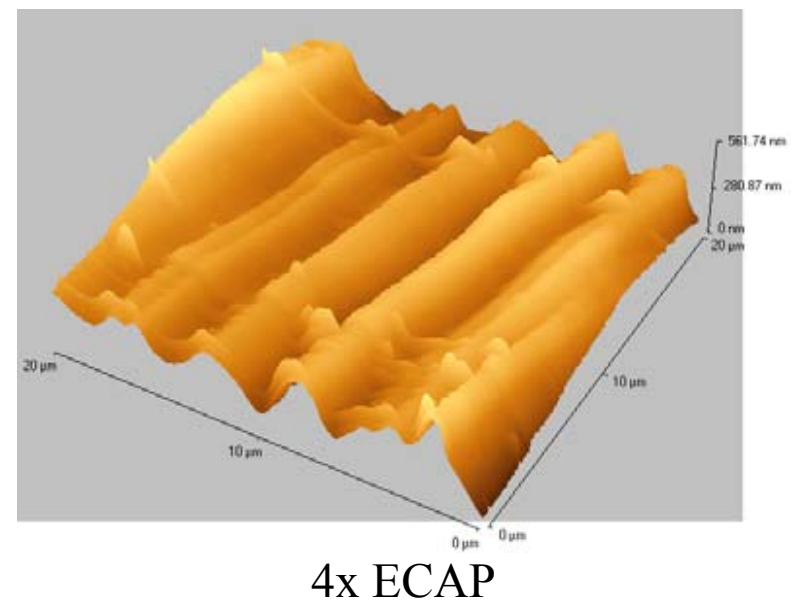

Fig. 8. Microscopy explosures in function of ECAP number

\section{References}

1 Moriwaki T, Okuda K, Machinability of Copper in Ultra-Precision Micro Diamond Cutting, Annals of the CIRP 38/1 (1989), 115-118, DOI 10.1016/S0007-8506(07)62664-X.

2 Spenrath N M, Technologische Aspekte zum Feinstdrehen von Kupferspiegeln, 1991. Diss. RWTH Aachen.

3 Prohászka J, The Effects of the Anisotropy of Young's Modulus on the Beginning of Plastic Deformation, Proceedings of IMMM '97, Mie University Press, 1997, pp. 13-20.

4 Von Turkovich B F, Black J T, Micro-machining of Copper and Aluminium Crystals, J. Eng. Ind. 92 (1970), 130-134, DOI 10.1115/1.3427697.

5 Komanduri-Chandrasekaran R N, Raff L M, Orientation Effects in Ultrafine metric Cutting of Single Crystal Materials: An MD Simulation Approach., Annals of CIRP (1999).

6 Grabchenko A, Horváth M, Mamalis AG, Mészáros I, Paulmier D, Ultraprecision Machining of Mirror-Surfaces, OSIN'99, Krakow, 1999, pp. 189-205.

7 Mamalis AG, Prohászka J, Mészáros I, The Effect of the Anisotropy of the Material on the Surface Topography in Case of Ultraprecision Machining, 1stEUSPEN Topical Conference on Fabrication and Metrology in Ultrafinetechnology, Copenhagen, 2000.

8 Nyírő J, Mamalis AG, Prohászka J, Mészáros I, Analysis of Ultraprecision Turned Mirror Surfaces, EUSPEN 2nd International Conference, in Turin; 2001.05.28-2001.05.31, 2001, pp. 718-721.

9 Gubicza J, Krallics Gy, Schiller I, Malgin D, Evolution of the microstructure of al 6082 alloy during equal-channel angular pressing, Materials Science Forum 473-474 (2005), 453-457, DOI 10.4028/0-87849-957-1.453.

10 Krállics Gy, Malgin D, Fodor A, Experimental investigations of the al 6082

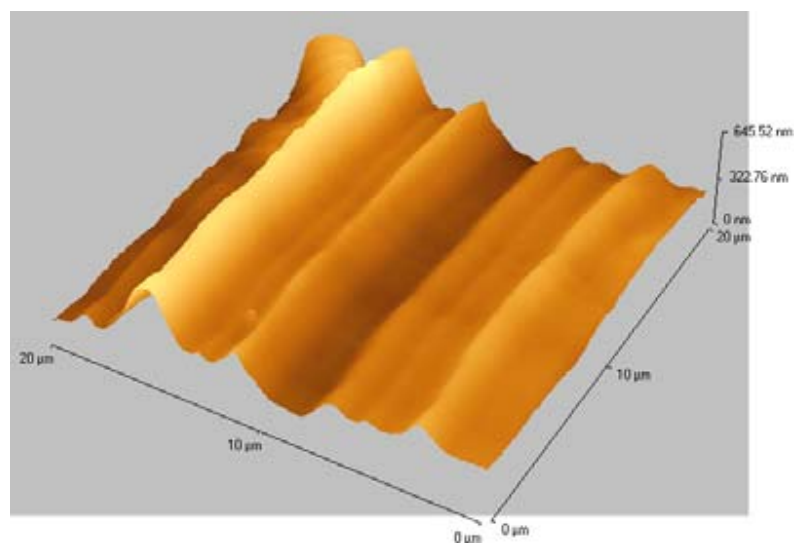

1x ECAP

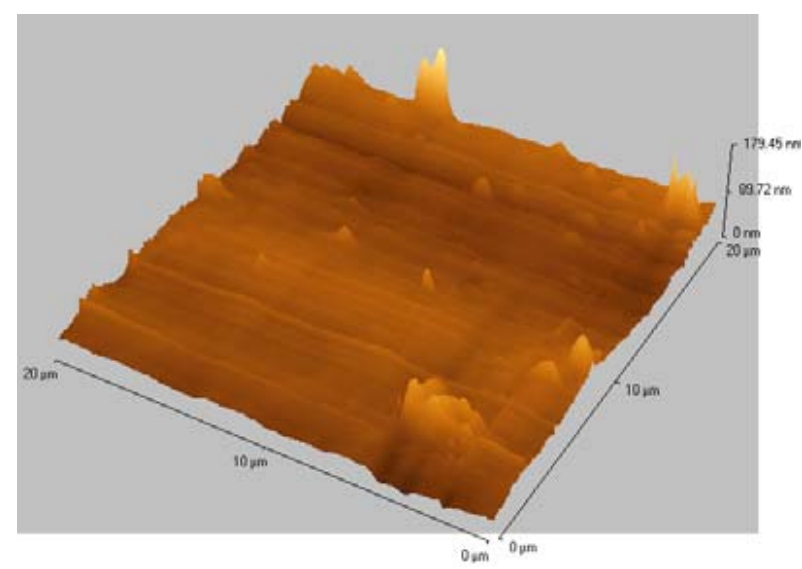

8x ECAP alloy subjected to equal-channel angular pressing, Materials Science Forum 473-474 (2005), 129-134, DOI 10.4028/0-87849-957-1.129.

11 Takács M, Mészáros I, Verő B, Krállics Gy, Dobránszky J, Törköly T, Machining of Ultra-Fine Grained Materials, VI. Hungarian Materials Science Conference, 2007.10.14-2007.10.16.

12 Gubicza J, Chin N Q, Krállics Gy, Schiller I, Ungár T, Microstructure of ultrafine-grained fcc metals produced by severe plastic deformation, Current Applied Physics 6 (2006), 194-199, DOI 10.1016/j.cap.2005.07.039.

13 Prohászka J, Dobránszky J, Nyírő J, Horváth M, Mamalis AG, Modifications of surface integrity during the cutting of copper, Materials and Manufacturing Processes 19 (2004), no. 6, 1025-1039, DOI 10.1081/AMP200035192.

14 Krállics Gy, Horváth M, Nyírő J, Forming and machining of the ultrafinecrystalline alloys, International conference on multi-material micro manufacture (4m). Grenoble, 2006.09.20-2006.09.22., pp. 239-242.

15 Prohászka J, Horváth M, Mamalis AG, Nyírő J, Effect of cutting tools and cut materials on integrity of mirror surfaces, Surface Engineering 22 (2006), no. 4, 294-298, DOI 10.1179/174329406X122874.

16 Prohászka J, Mamalis AG, Horváth M, Nyírő J, Dobránszky J, Effect of Microstructure on the Mirror-Like Surface Quality of FCC and BCC Metals, Materials and Manufacturing processes 21 (2006), no. 7-8, 810-818, DOI 10.1080/10426910600837806. 